\title{
A TEORIA DA DEPENDÊNCIA COMO MATRIZ PARA UM DIÁLOGO LATINO-AMERICANO
}

\author{
Marcelo Freddi Lotufo \\ marcelo_lotufo@brown.edu
}

Pensar a relação entre o Brasil e a América Hispânica, o desafio proposto por Jorge Schwartz em seu hoje clássico ensaio "Abaixo Tordesilhas!", tem se mostrado um prolífico campo de estudos comparados. Ao questionar a pouca interação entre as literaturas lusófonas e hispânicas na América, é a ausência de um diálogo sistemático entre os pensamentos críticos brasileiros e dos demais países do continente o que mais parece incomodar o crítico. E com razão. Não pareceria acertado cobrar da literatura propriamente dita, que não tem obrigação de ser sistemática, o estabelecimento de elos e pontes entre as regiões. Seria a crítica, menos preocupada com sua própria liberdade e jouissance, ainda que em tempos modernos tais divisões possam ser bastante tênues, que teria a tarefa de criar este ambiente de troca, além de pensar as possibilidades e limites de tal diálogo. Entretanto, de acordo com Schwartz, a falta de continuidade dos diálogos entre o Brasil e os demais países da América Latina, os quais parecem recomeçar a cada geração, dificulta a aproximação entre os pensamentos dos países do continente.

A necessidade de se recuperar tais projetos comparados, o que fomentaria a sedimentação de uma tradição conjunta e facilitaria o diálogo entre as diferentes literaturas do continente, já gerou direta e indiretamente interessantes estudos e parece ser um campo promissor para a história intelectual latino-americana. Em anos recentes, não 
só novas relações têm sido estabelecidas, mas antigos diálogos que pareciam esquecidos também foram redescobertos. ${ }^{1}$ Recuperar esses diálogos feitos por gerações passadas é uma tarefa central no combate ao ciclo vicioso de esquecimento e indiferença que nos afeta e do qual fala Schwartz. É, também, uma maneira de retomarmos temas e discussões que não chegamos a esgotar, mas que são de suma importância para a compreensão de nossa realidade, como os debates sobre centro e periferia, subdesenvolvido e desenvolvido, ou sobre nossa dependência epistemológica em relação aos centros culturais, todos temas que, de certa forma, dizem respeito tanto ao Brasil como a seus vizinhos latino-americanos e que poderiam ser retomados a partir de desenvolvimentos teóricos contemporâneos. Com isso em mente, proponho que voltemos nossa atenção a um debate específico, o da noção de dependência, que foi marcado tanto por um caráter continental como pela preocupação com os problemas e desafios sociais enfrentados pela América Latina; um debate caro ao Brasil, mas que, ao que tudo indica, começa a ser esquecido, mesmo quando as novas crises econômicas e políticas que afetam o continente parecem confirmar a importância e validade desse debate.

${ }^{1}$ Para não repetir os exemplos já apontados pelo próprio Schwartz em 1992, limito-me aqui a dois estudos mais recentes que, por não terem sido publicados no Brasil, não receberam da crítica brasileira a atenção que mereciam. Refiro-me, primeiro, ao livro de Robert Newcomb, intitulado Nossa and Nuestra América: inter-american dialogues (2011) que, além de dialogar diretamente com o ensaio de Schwartz, explora as relações, nem sempre explícitas ou creditadas, entre o pensamento de alguns intelectuais centrais para as Américas, como José Henrique Rodó, Joaquim Nabuco, Alfonso Reyes e Sérgio Buarque de Holanda, e investiga como cada intelectual pensou no início do século XX o continente latino-americano. O segundo estudo, voltado para o século XIX e, talvez, para o que tenha sido o primeiro diálogo do período pós-colonial entre as Américas Hispânicas e Lusófonas, o livro de Adriana Amante, Poéticas y políticas del destierro: argentinos en Brasil en la época de Rosas (2010), publicado em espanhol pela editora mexicana Fondo de Cultura Económica. Nesse livro, Amante recupera o interessante diálogo entre as primeiras gerações românticas brasileira e argentina e, principalmente, investiga o exílio de escritores argentinos no Brasil durante o governo do caudilho Juan Manuel de Rosas (1832-1852). Escritores centrais para a literatura argentina, como Domingo Faustino Sarmiento e José Mármol, por exemplo, passaram parte de seus exílios no Rio de Janeiro, participando, inclusive, da vida intelectual brasileira durante um período em que, como aponta Antonio Candido, o sistema literário brasileiro se formava. Além de Amante, Maria Eunice Moreira recentemente se debruçou sobre o tema, publicando o ensaio "Hermanos e irmãos: as relações literárias entre os românticos argentinos e brasileiros durante o romantismo", na revista Teresa, n. 12-13 (2012-2013), publicação da pós-graduação em literatura brasileira da Universidade de São Paulo. 
Por estar primeiramente associada com a sociologia dos anos 1960 e 1970, com nomes como Fernando Henrique Cardoso, Enzo Faletto e Ruy Mauro Marini, e não propriamente com os estudos da cultura, pouca atenção tem sido dada para os "achados" culturais da "teoria da dependência". Esses debates foram de extrema importância para a crítica literária brasileira e latino-americana. ${ }^{2}$ Noções como "as ideias fora do lugar", de Roberto Schwarz, e "colonialidade do poder", de Aníbal Quijano, dificilmente seriam possíveis sem os debates em torno da ideia de dependência. Explorar a relação desses críticos culturais com esses debates abre a possibilidade para pensarmos seus trabalhos de forma comparativa dentro da própria América Latina. Ademais, o recente interesse por teorias sistêmicas da literatura, ligado ao renascimento dos debates de "literatura mundial", proposto principalmente pelos críticos Franco Moretti e Pascale Casanova, recuperou a noção de teorias sistêmicas da literatura e tem trazido teorias como as da dependência de volta ao centro dos debates culturais, ainda que a partir de suas leituras europeias e norte-americanas. Seria o caso, assim, de a própria América Latina retornar a esse debate, e pensar tanto na relação entre os diferentes países do continente como em seu lugar nas trocas literárias mundiais.

Para tanto, proponho dividir este ensaio em quatro partes. Primeiro uma recapitulação do que seria a "teoria da dependência" e sua insistência em uma matriz continental baseada no diálogo. Segundo, uma análise do pensamento de Roberto Schwarz e de sua relação com a teoria da dependência, explorando como seu pensamento, mesmo quando focado no Brasil, é intrinsecamente comparativo e convida-nos a aproximá-lo dos demais países da América Latina. Em seguida, ofereço uma análise de como Aníbal Quijano, a partir do Peru, levanta, também a partir da "teoria da dependência", questões semelhantes às de Schwarz, ainda que as soluções apresentadas sejam outras. Por fim, concluo mostrando como a comparação entre esses teóricos pode ser prolífica e como podemos, por meio desses debates, pensar a América Latina de uma forma dialética, que visa preservar tanto o local como o global, tanto o nacional como o continental; e como problemas e soluções de um crítico podem esclarecer pontos menos trabalhados por outro.

2 Tema explorado em Lotufo, Marcelo. "O papel da Teoria da Dependência em Roberto Schwarz”. Hispania, n. 97.4, p. 589-599, dez. 2014. 


\section{TEORIA DA DEPENDÊNCIA}

“Teoria da dependência”, mais que um conceito propriamente dito, foi um movimento teórico e político que surgiu na América Latina nos anos 1960 e 1970. Diante da crescente industrialização pela qual passava o continente no período, sem que esta alterasse certas estruturas sociais e políticas da região, intelectuais latino-americanos começaram a questionar as teorias de desenvolvimento econômico e social que estavam em voga desde o final da Segunda Guerra Mundial e que não pareciam apresentar respostas para a situação ambígua do continente. Alguns dos pensadores mais conhecidos desse movimento foram o economista alemão Andre Gunder Frank, os brasileiros Fernando Henrique Cardoso, Paul Israel Singer, Ruy Mauro Marini, o sociólogo chileno Enzo Faletto, o mexicano Paulo González Casanova e o filipino Walden Bello. Um tema complexo, a "teoria da dependência", suas diferentes correntes e propostas, transcende o escopo deste ensaio. Nem sempre os teóricos concordavam em suas soluções teóricas para o problema que enfrentavam, ainda que todos reconhecessem sua presença. Interessa aqui, entretanto, entender qual era a questão principal que informou esses debates: a saber, como se pensar desenvolvimento econômico de forma dinâmica na periferia do capitalismo, levando-se em conta os caracteres nacional, continental e global dos processos históricos e econômicos que informaram o continente.

Se após a Segunda Guerra e até meados dos anos 196o, seguindo os paradigmas estabelecidos por W. W. Rostow e pelos Estados Unidos por meio da conferência de Breton Woods (1944), desenvolvimento econômico era um processo pensado de forma linear, no qual não-desenvolvido, subdesenvolvido e desenvolvido eram estágios diferentes em uma estrada única, a dinamicidade das economias latino-americanas nos anos 1960 e 1970 passou a questionar a simplicidade do modelo proposto. Isto é, se desenvolvimento fosse simplesmente uma questão de repetir os passos anteriormente seguidos pelas potências econômicas (Estados Unidos, os países do Oeste europeu, Japão etc.), por que o rápido desenvolvimento industrial do período não parecia levar o continente latino-americano ao estágio desenvolvido, alterando sua estrutura social e política? Desenvolvido, subdesenvolvido e não desenvolvido pareciam, vistos da periferia, conviver pacificamente em um mesmo sistema, ao invés de, como se pensara até então, serem etapas a serem superadas e pertencentes 
a épocas históricas diferentes. O futuro da América Latina não parecia ser a Europa, e o passado dos Estados Unidos não se parecia, no fim, com o Brasil contemporâneo. Para esses críticos, as condições específicas do desenvolvimento pelo qual passava a América Latina eram próprias de seu momento histórico e da posição que ocupava em um sistema capitalista global. Nas palavras de Saldaña-Portillo, para esses teóricos

\begin{abstract}
desenvolvimento e subdesenvolvimento eram simultaneamente modernos; subdesenvolvimento não era nem originário (precursor) e nem tradicional (arcaico); desenvolvimento não era nem autônomo nem racionalmente dependente... A teoria da dependência, ao perturbar o progresso natural e em etapas da narrativa do desenvolvimento, desnaturaliza o desenvolvimento capitalista e desnacionaliza a teoria do desenvolvimento, instituindo uma análise verdadeiramente global (2003, p. 55). ${ }^{3}$
\end{abstract}

No caso específico do Brasil, a "teoria da dependência" também vinha questionar pressupostos estabelecidos pela geração que pensara, nos anos 1950 e início dos anos 1960, os termos, limites e possibilidades do desenvolvimento brasileiro. Eram intelectuais como Nelson Werneck Sodré e Celso Furtado que, em grande parte através do Instituto de Ensino Superior Brasileiro (Iseb), haviam estabelecido as bases para os projetos econômicos nacionalistas tanto de direita como de esquerda no país (CARDOSO, 1993, p. 86). Fora o Iseb que, de certa forma, estivera por trás do nacional desenvolvimentismo que marcara o governo de Juscelino Kubistchek e que, com o golpe de 64, mostrava seus limites estruturais. O moto do governo Kubitschek, "Cinquenta anos em cinco", é emblemático das noções de desenvolvimento que a teoria da dependência viria combater e que fora elaborado pelo Iseb. Subdesenvolvimento era o passado do desenvolvimento e, de certa forma, com um grande esforço nacional, seria possível tirar o "atraso" do país, avançando cinquenta anos em cinco e igualando-nos às potências industriais avançadas.

Se tomarmos como base de comparação o trabalho de Fernando Henrique Cardoso e Enzo Faletto, Dependência e desenvolvimento na América Latina (1970), a crítica proposta ao modelo linear de desenvolvimento por etapas é clara. Desenvolvimento, para esses autores, não é uma questão de se seguir passos predefinidos, mas sim um desafio que envolve lidar tanto com um sistema capitalista global e

3 Todas as traduções do inglês são minhas. 
monopolista, como com a realidade especifica de cada país. O problema era, exatamente, mostrar "de forma mais direta e específica como se dá a relação e que implicações derivam da forma de combinação que se estabelece entre economia, sociedade e política em momentos históricos e situações estruturais distintas" (p. 7). Isto é, subdesenvolvimento, para Cardoso e Faletto, não era simplesmente uma questão de "atraso," mas sim uma questão complexa que precisava levar em consideração tanto a realidade específica de cada país quanto o estado atual do capitalismo global, atentando não somente para a economia, mas também para a realidade sociopolítica de cada região.

O salto dialético proposto por esses autores foi entender que subdesenvolvimento não era um problema local, mas que, principalmente quando visto da periferia, era uma condição necessária ao próprio capitalismo. Isto é, desenvolvimento e subdesenvolvimento eram faces da mesma moeda e o primeiro necessitava do segundo, de seus mercados e matérias-primas para manter sua posição hegemônica. Dentro dessa realidade global, entretanto, desenvolver-se não era uma tarefa simples, pois no momento histórico em que os países latino-americanos se industrializavam, também competiam por mercados (inclusive os seus próprios) e por recursos naturais e financeiros com os países já desenvolvidos, estando sempre em uma situação desvantajosa, pois não possuíam a mesma acumulação de capital que essas nações. Ademais, essa menor acumulação levava o continente a buscar empréstimos em países que possuíam maiores reservas, aumentando exponencialmente suas dívidas e pagando juros que financiavam seus concorrentes; e isso sem falar na posição de inferioridade política em que esses empréstimos e dívidas deixavam os governos latino-americanos no cenário internacional.

Entender o fenômeno da dependência, portanto, passava por pensar a relação desses estados periféricos entre si e, também, com os demais países do sistema capitalista: o sistema era tanto nacional como continental e global. A relação mais direta entre o local e o global, para Cardoso e Faletto, dava-se através das elites políticas nacionais, as quais faziam o papel de mediador entre capital internacional e mercados e recursos nacionais. Isto é, para investir em um país e explorar seus recursos e mercados, o capital precisaria ser filtrado pelo estado de cada país, por suas leis, interesses e projetos. Assim, esse capital internacional necessitaria relacionar-se com as elites periféricas que, em troca, também lucrariam com esses investimentos, podendo, inclusive, acumular o 
capital que lhes faltava e reverter a condição subdesenvolvida de seus países. Por necessitar desse mediador, o capital internacional participava do jogo político de cada país; daí, por exemplo, as muitas "repúblicas de bananas" que surgiram no continente. O capital, por meio de estados nacionais, brigava para defender seus interesses e manter elites amigas e pacíficas nos países em que investia. Desenvolvimento econômico, nessa lógica, era também um problema político. Crescimento econômico, assim, não levaria necessariamente a desenvolvimento social; tudo dependeria da pressão popular ou do altruísmo de uma elite já constituída e que se beneficiava do sistema que, em tese, precisava consertar.

As elites de cada país, contudo, são específicas e variam de acordo com inúmeros fatores, dependendo da matriz econômica, das possibilidades geográficas, da extensão territorial, da estabilidade política e de outros incontáveis fatores. Para esses teóricos, portanto, a América Latina não podia ser entendida somente como um grande bloco homogêneo: era preciso, também, entender sua diversidade. O livro de Faletto e Cardoso é, novamente, emblemático. Após uma introduçãogeral, os críticos procuram explicar as especificidades de cada país do continente, oferecendo análises nacionais para a maioria dos países da região. Cada elite política, junto com os interesses do capital internacional, estaria em grande parte por trás das condições de possibilidade para o desenvolvimento de cada país específico. Se a elite argentina se desenvolvera principalmente através da exploração agrário-exportadora e possibilitara a criação de uma classe média dinâmica, no Brasil a presença mais forte do trabalho escravo dificultara a formação de uma classe média e fortalecera certa oligarquia que manteria o governo imperial por quase todo o século XIX. Na Argentina, entretanto, o confronto entre as elites mercantis bonaerenses e as elites agrárias do interior dificultou a estabilidade política do país, deixando suas elites em posições mais fragilizadas. Em suma, as condições de possibilidade para o desenvolvimento socioeconômico do Brasil e da Argentina dependiam de suas histórias específicas, dos interesses e projetos de suas elites, que eram bastante diferentes entre si, além, logicamente, da relação que essas elites nacionais estabeleceram com o capital internacional.

Um projeto de cunho continental como o da "teoria da dependência", que procura entender cada país também em suas particularidades, dificilmente existiria sem diálogo e trocas. Não sem certa ironia, tal projeto crítico beneficiou-se do fluxo de intelectuais que, devido às diversas ditaduras militares que se formaram no continente latino-americano, 
precisaram sair de seus próprios países (SALDAÑA-PORTILLO, 2003, p. 48). Escrito a quatro mãos, o livro de Cardoso e Faletto, por meio de notas de rodapé e de sua bibliografia, deixa claro sua dívida com o ambiente de troca e debates que se instaurara na região durante o período. Posteriormente, Cardoso iria enfatizar a dívida que os trabalhos em torno da noção de dependência teriam em relação à Cepal que, de certa forma, iniciou esse diálogo continental, ainda que limitado e mediado pelos órgãos aos quais a comissão se filiava (principalmente as Nações Unidas). Por meio desses diálogos, a "teoria da dependência” pensou a América Latina, suas partes lusófona e hispânica, como uma região dinâmica que só poderia ser entendida por meio de um esforço conjunto, em que se levasse em conta tanto o local como o global; e no qual subdesenvolvido e desenvolvido não fossem termos temporalmente consecutivos, mas sim termos contemporâneos que dependiam um do outro para existir. A crítica dos pensadores latino-americanos aos modelos globais, assim, oferecia maior dinamicidade para a periferia e tentava fugir de uma simplicidade que favorecia econômica e culturalmente os países centrais, protegendo sua hegemonia. Tais achados da sociologia e economia também teriam um importante papel nos debates da cultura e ajudariam o continente a repensar paradigmas que se mantinham em voga desde o século XIX, como a suposta superioridade da cultura europeia, ou a impossibilidade de se produzir boa literatura na América Latina.

\section{DESENVOLVIMENTOS CULTURAIS: "AS IDEIAS FORA DO LUGAR"}

O desdobramento cultural mais conhecido dos debates em torno da dependência, ao menos no Brasil, é o estudo do crítico cultural Roberto Schwarz denominado "As ideias fora do lugar". Não é preciso muito para se mostrar a relação de Schwarz com os problemas propostos pela "teoria da dependência”. O próprio autor inúmeras vezes falou de sua relação pessoal com Cardoso, seja na Universidade de São Paulo, no seminário de Marx ou no Centro Brasileiro de Pesquisa (Cebrap) (SCHWARZ, 1999, p. 86-105). Mais do que buscar uma influência, o que interessa aqui é percebermos como a preocupação central da "teoria da dependência", a compreensão de centro e periferia como determinados historicamente e como parte de um jogo dialético, também é central para as propostas de 
Schwarz. ${ }^{4}$ Ao questionar a simplicidade com que modelos teóricos eram adotados e aplicados no Brasil, Schwarz rearticula os achados da "teoria da dependência" para o âmbito da cultura, preservando o caráter comparado e dinâmico daquele debate. Isto é, ele atenta para as peculiaridades nacionais sem perder de vista as relações sociais e literárias globais, buscando entender como o local é afetado pelos modelos e processos internacionais, mas também como estes afetam o global. E, mesmo que o crítico foque seu trabalho no caso brasileiro, sua matriz pode facilmente ser estendida para se pensar o resto da América Latina ou, como aponta Franco Moretti, para grande parte da literatura produzida fora dos centros hegemônicos da cultura (2004, p. 148-162).

A pergunta que propõe Schwarz em seu conhecido ensaio deixa claro o caráter comparativo de seu modelo: "Que valiam, nestas circunstâncias", de um país marcado pelo favor e pela escravidão, "as grandes abstrações burguesas que usávamos tanto?” (1981, p. 14). Isto é, no lugar periférico a que pertencia o Brasil no século XIX, qual seria o sentido de certas formulações universalizantes e modernas surgidas nas revoluções burguesas da América do Norte e da Europa? Qual o significado, para ficar no exemplo mais famoso, do grito de "liberdade, igualdade e fraternidade" da Revolução Francesa em um Brasil escravocrata? Ou, ainda, o que fazer da ênfase em "direitos" da "Declaração Universal dos Direitos do Homem e do Cidadão" em um país marcado pelo favor e pela cordialidade? Para Schwarz, estas abstrações culturais, assim como investimentos financeiros, seriam mediadas pelas relações sociais específicas de cada país, o que lhes daria um caráter próprio, isto é, no caso do Brasil, tais processos dariam um caráter de "independência à dependência, utilidade ao capricho, universalidade às exceções, mérito ao parentesco, igualdade ao privilégio" (1981, p. 18).

Esse desencontro seria a pedra de toque para se entender nossa vida cultural, o que não significava que ele dizia respeito somente aos países periféricos. Tal relação era um sintoma do próprio capitalismo e dizia respeito, também, aos países centrais. Nas palavras de Schwarz, "é

4 Vale ressaltar que os problemas da dependência possuem um caráter de "Zeitgeist" no período e, assim, as influências de Schwarz vinham também de outras partes. A problemática do desenvolvimento se tornará central também para pensadores como Antonio Candido e Paulo Emilio Salles Gomes. Ver, por exemplo, "Literatura e subdesenvolvimento", do primeiro, e Cinema: trajetória no subdesenvolvimento, do segundo. 
inevitável este desajuste ao qual estávamos condenados pela máquina do colonialismo, e ao qual, para que fique indicado seu alcance mais que nacional, estava condenada a mesma máquina quando nos produzia” (1981, p. 22). Como aponta Fredric Jameson em The Modernist Papers, os próprios modelos centrais, como, no caso da literatura, as vanguardas modernistas, estavam intrinsecamente (e formalmente) ligadas ao expansionismo colonial europeu e não teriam existido da mesma forma sem ele. Para Schwarz, esta relação entre formas internacionais e relações locais, portanto, segue a mesma lógica da estabelecida pela "teoria da dependência” para trocas econômicas. Tais modelos ideológicos seriam filtrados e transformados pelas relações sociais locais. E, em ambos os casos, o local e o global se mostrariam como lados da mesma moeda e, hegelianamente, precisariam um do outro para existir. A dependência cultural da periferia seria, assim, o que garantiria a hegemonia do centro e permitiria sua existência como centro, enquanto esta mesma relação manteria a periferia em um lugar dependente, em que se valorizam somente os desenvolvimentos culturais centrais.

Contudo, no caso da cultura, dependência não seria dependência de capitais estrangeiros, mas sim uma dependência epistemológica que marcaria o pensamento e a cultura desses países. Estaríamos condicionados pelo sistema e por nossa história a copiar as ideias vindas de fora, sem necessariamente pensar em sua validade para nosso contexto específico, ou articulá-lo com nossos próprios conhecimentos. Nesse processo, formas, conceitos e ideias consagrados na Europa e América do Norte passariam pela mediação das relações sociais locais para sobreviverem em um novo contexto, ganhando novos sentidos. $\mathrm{Na}$ literatura, por exemplo, o narrador burguês, defensor de certos princípios e de uma totalidade em autores como Honoré de Balzac e Victor Hugo, ver-se-ia face a face com uma realidade na qual sua ideologia estava distante até mesmo daquilo que procurava esconder ou criticar. Isto é, na periferia, ideologia assumiria, para usar o termo do próprio Schwarz, um caráter de segundo grau, mais distante da realidade que tentava mascarar, combater ou entender. Todavia, no caso cultural, dependência não era necessariamente negativa, como era o caso na economia. Por causa de sua condição subdesenvolvida, de "dentro do seu atraso histórico, o país impunha ao romance burguês uma realidade mais complexa” (1981, p. 23). Isto é, diferentemente da dependência econômica, fenômeno que teria sempre um caráter negativo, na literatura a condição de dependência podia 
produzir respostas originais e de qualidade para a condição periférica dos próprios autores. Isso, entretanto, não mudaria o caráter subdesenvolvido e dependente do país.

Assim, pensando literatura a partir de uma matriz que deriva da “teoria da dependência”, Schwarz consegue preservar a autonomia do fenômeno cultural, sem abrir mão da crítica social. Isto é, as questões sociais, centrais para o crítico, estariam dialeticamente ligadas às questões culturais, sem taxar estas necessariamente de menores ou secundárias. Independentemente da qualidade inquestionável de um autor como Machado de Assis, ainda poderíamos dizer que as relações de favor, corrupção e exploração, centrais para seus romances, eram negativas e precisavam ser combatidas. Não era porque tais relações ofereciam material para uma grande literatura que deixavam de representar atraso. Como Falleto e Cardoso, portanto, Schwarz procura articular avanços, em seu caso desenvolvimentos literários, com questões sociais atrasadas, sem deixar de ser crítico ao subdesenvolvimento que estas representavam.

Outro aspecto do trabalho de Schwarz que, quando visto a partir da “teoria da dependência”, ganha novas cores é o caráter comparativo de seu projeto. Além da óbvia comparação dos desenvolvimentos locais com as matrizes centrais, a condição periférica que marca grande parte do globo convida à expansão de seu modelo para outras regiões. Tal expansão ajudaria a entendermos a complexidade dos processos pelos quais ideologias centrais são transformadas em diferentes contextos. O próprio crítico aponta para esta possibilidade ao comparar, ainda que en passant, a literatura brasileira com a Russa (1981, p. 23-24). De algum modo, tal comparação poderia ser estendida à própria América Latina. Os diversos países do continente, afinal, partilham um passado ligado ao colonialismo ibérico que, apesar de ter deixado diferentes marcas em cada região do continente, transformou todos os países em fornecedores de matéria-prima e consumidores de produtos e ideias europeias e, posteriormente, norte-americanas. Restaria entender como, a partir de sua realidade específica, cada país transformava os mesmos modelos europeus.

No caso da literatura, muitas das formas centrais que circulavam no Brasil também circulavam nos demais países da América Latina. Se compararmos, por exemplo, os Primeiros cantos (1846) de Gonçalves Dias com as Rimas (1837) do poeta argentino Esteban Echeverría, fica clara a semelhança entre as matrizes dos dois autores. Suas epígrafes, por exemplo, remetem quase sempre ao mesmo cânone romântico europeu, 
indo de Victor Hugo a Wolfgang von Goethe e Germaine de Staël. Ainda assim, seus livros são bastante diferentes, principalmente em seus melhores poemas. Ainda seguindo o modelo de Schwarz, as condições locais, principalmente as políticas, parecem levar ambos os autores a desenvolverem projetos literários bastante diferentes (AMANTE, 2010). Se Dias ajuda a criar a iconografia que dará sustentação ideológica ao governo de Dom Pedro II, Echeverría usa sua obra para criticar e acusar o governo de Juan Manuel de Rosas, escrevendo uma poesia mais crítica e questionadora que a de Dias. As possibilidades comparativas, a partir do trabalho de Schwarz, assim, são claras e nos permitem pensar a América Latina tanto em sua diversidade como em sua unidade, e sem abrirmos mão da crítica social.

\section{DESENVOLVIMENTOS CULTURAIS: “COLONIALIDAD DEL PODER"}

Como aponta Walter Mignolo, “colonialidade do poder”, assim como as "ideias fora do lugar", também tem uma importante "dívida com a teoria da dependência" (2008, p. 239) e se preocupa com o "aspecto político e dialético" (p. 251) daquele fenômeno. Isto é, assim como Schwarz, Quijano também procura entender subdesenvolvido e desenvolvido, ou centro e periferia, não em termos teleológicos ou temporais, mas sim como contemporâneos e centrais para a existência um do outro. Como para os demais críticos aqui estudados, para Quijano os desenvolvimentos políticos, culturais e econômicos que marcaram a América não diziam respeito somente ao continente, mas eram importantes para entendermos as dinâmicas do capitalismo global e parte dos processos formativos do próprio centro.

Para o crítico peruano, para entendermos nosso momento contemporâneo e seus desenvolvimentos culturais, precisaríamos atentar para os desenvolvimentos ideológicos que marcaram tanto a América Latina como a Europa durante o colonialismo ibérico. Precisávamos entender a lógica dependente que marcou o continente no período e as formas pelas quais o "ser periférico" e o "ser central" se manifestaram após o fim do colonialismo ibérico. Só assim, nas palavras de Quijano e Imanuel Wallerstein, poderíamos entender por que "las Américas se preparan a ingresar en el siglo XXI casi con las mismas desigualdades 
que en el siglo XIX" (1992, p. 590). Isto é, só assim entenderíamos por que os desenvolvimentos culturais, sociais e econômicos da América Latina não parecem transformar a realidade social do continente e sua lógica dependente, mas sim contribuíam para preservar desigualdades e, até mesmo, um lugar periférico no sistema global. Não por acaso, esta é, mutatis mutandis, a mesma questão que os teóricos da dependência se propuseram.

A reposta de Quijano, assim como o achado de Schwarz, passa pelo reconhecimento da dependência epistemológica que, historicamente, marcara a cultura latino-americana. O ciclo vicioso que parecia limitar a América Latina, para Quijano, passava pela ideia de que as elites do continente deviam copiar as elites europeias; e pelo fato de essas elites nacionais, nesse processo, continuarem agindo como elites coloniais, mesmo quando essas práticas dificultavam o desenvolvimento das economias periféricas e dessas próprias elites. Isto é, a certeza de que desenvolvimento cultural e econômico se davam de forma teleológica, numa linha na qual a Europa estava anos à frente da América e precisava ser alcançada, levava as elites culturais e políticas latino-americanas a identificarem-se com as elites europeias, apostando que copiá-las era o melhor que poderiam fazer para alcançá-las. Nessa lógica, entender as necessidades específicas de seus países e tentar repensar sua história de forma independente dos preconceitos coloniais não era uma tarefa prioritária. A mesma noção de desenvolvimento teleológico que a teoria da dependência viera combater, portanto, também marcava as elites culturais da América Latina, fazendo-as adotar uma visão de mundo eurocêntrica contrária aos interesses coletivos desses países.

Assim, a visão de mundo adotada pelas elites americanas era uma visão de mundo que surgira na Europa durante o colonialismo. As duas visões, dos colonizados e colonizadores, eram praticamente uma. Isto é, a visão colonial de mundo foi naturalizada como uma visão eurocêntrica, algo verdadeiro tanto no centro quanto na periferia, ainda que as consequências mais palpáveis e cruéis desse fenômeno fossem percebidas com maior facilidade na periferia do sistema capitalista. Esta normalização de uma visão colonial do mundo é o que Quijano denominará “colonialidade do poder". Esta, para Quijano, seria uma visão de mundo marcada pela divisão do planeta em termos raciais e pela suposta superioridade da raça e cultura europeias. Portanto, o que caracterizaria o início do período moderno não era para ele os ideais de igualdade da Revolução Francesa, por exemplo, 
mas sim a lógica da escravidão e opressão que surgiu a partir das divisões do mundo em raças avançadas e atrasadas; uma visão de mundo que, com a posterior expansão colonialista para a Ásia e a África, alcançaria o mundo capitalista em sua totalidade. "Colonialidade do poder", portanto, perpassava em grande medida todo o pensamento moderno. E, no caso da América Latina, a intensa imigração de europeus para o continente e a constituição de uma elite que até mesmo fenotipicamente se identificava com a Europa, levaria essa perspectiva a ser facilmente aceita; enquanto na Índia ou na China, onde a proximidade das elites nacionais com as culturas autóctones dessas regiões era maior, esse processo teria encontrado maior resistência. Na América Latina, entretanto, mesmo após a independência política do continente, o processo de apagamento de culturas autóctones e afrodescendentes, iniciado durante o colonialismo ibérico, continuou avançando.

Uma visão de mundo criada em oposição a um "outro" colonizado e supostamente inferior, só poderia dar-se através de um complexo processo que envolveu, além de violência, de relações econômicas predatórias e da própria escravidão, um longo processo de apagamento e apropriação das culturas nativas das Américas. O convencimento das elites americanas de que estavam mais próximos dos povos europeus do que dos povos e classes subjugadas de seus países fez com que ignorassem as civilizações ameríndias que ali havia, reificando esses povos como mão de obra barata. A riqueza dessas culturas, sua variedade e suas diferentes histórias acabaram suprimidas e incorporadas sob o nome genérico de escravos ou índios. Diversos povos com história própria e sistemas de pensamento únicos foram, nessa lógica, marcados como atrasados ou primitivos e vistos como o passado da raça branca. Por isso, suas histórias e práticas foram descartadas como ultrapassadas. Foi dentro dessa perspectiva, por exemplo, que se justificou a imigração europeia para a América no final do século XIX, pois não seria inteiramente possível integrar as raças atrasadas ao processo civilizatório. Seria necessário branqueá-las, apagando-as de vez; ou mantê-las em uma posição subalterna e inferior, de modo que não atrapalhariam o progresso das elites. Em suma, nas palavras do próprio Quijano,

La dependencia de los señoriales de esos países tenía en consecuencia una fuente inescapable: la colonialidad de su poder los llevaba a percibir sus intereses sociales como iguales a los de los otros blancos dominantes, en Europa y en Estados Unidos. Esa misma colonialidad del poder les impedía, sin embargo, desarrollar realmente sus intereses sociales en la misma dirección 
que los de sus pares europeos, esto es, convertir capital comercial (beneficio producido lo mismo en la esclavitud, en la servidumbre, o en la reciprocidad) en capital industrial, puesto que eso implicaba liberar indios siervos y esclavos negros y convertirlos en trabajadores asalariados (2000, p. 253).

É, portanto, a adoção deste ponto de vista eurocêntrico, de uma "colonialidade do poder", o que marca, para Quijano, a vida intelectual das elites latino-americanas. Para se pensar o continente de forma independente e crítica, seria necessário romper com esse posicionamento e voltar nossa atenção para culturas subalternas sem os preconceitos que historicamente marcaram sua recepção; seria necessário repensar os próprios conceitos com que as pensamos pois, estes também, teriam sua origem marcada em grande parte por esta lógica colonialista (MIGNOLO, 2008, p. 247). Entender as consequências e manifestações "da colonialidade do poder" em cada país seria, assim, o passo seguinte para se combater a dependência epistemológica e seus preconceitos em nossos próprios modelos analíticos, para não falar em nossas vidas e práticas cotidianas.

É interessante perceber, no escopo deste trabalho, como o foco de Quijano não se limita somente à escravidão, entendida como forma produtiva, mas abre o debate para uma questão mais ampla de identidades subalternas. Se a questão das "ideologias de segundo grau” para Schwarz estava ligada principalmente à presença escrava qua modo de produção no Brasil, para Quijano, que tem no Peru seu exemplo central, escravidão é, mesmo no século XIX, somente um modo de produção e exploração entre outros; servidão e arrendamento, por exemplo, eram tão presentes quanto a escravidão no Peru e foram usados para subjugar as populações ameríndias daquele país. ${ }^{5}$ Assim, ao invés de procurar um modo hegemônico de exploração e buscar suas consequências epistemológicas, Quijano foca na diversidade de identidades que os processos de subjugação colonial apagaram. Assim, preconceito, logicamente em grande parte advindo do próprio sistema escravista, está no centro de "colonialidade

${ }_{5}^{5}$ Como apontara José Carlos Mariátegui no início do século XX, era central para o Peru pensar a questão indígena e tentar integrá-la aos debates marxistas, algo que o modelo de Quijano tenta articular. Mariátegui escreve, por exemplo, em seu Siete ensayos de interpretación de la realidad peruana, que "la nueva generación peruana siente y sabe que el progreso del Perú será ficticio, o por lo menos no será peruano, mientras no constituya a la obra y no signifique el bien estar de la masa peruana que en sus cuatro quintas partes es indígena y campesina" (2011, p. 38). 
do poder". Para se combater tal visão de mundo e uma cultura fundada sobre preconceitos, seria necessário recuperar a diversidade das culturas ameríndias e afrodescendentes na América e, a partir dali, repensarmos nossa própria história intelectual, agora de forma menos dependente; ou ao menos mais consciente de nossos próprios preconceitos e limitações.

\section{CONCLUSÃO: O DIÁLOGO COMO RESPOSTA}

Devido ao escopo e objetivo deste estudo, limitei-me a uma descrição rápida de suas ideias, tentando enfatizar como através da "teoria da dependência" ambos os pensadores parecem compartilhar certas preocupações, com ênfase na dependência epistemológica que marcou a vida cultural da América Latina. Ademais, a "teoria da dependência” coloca em evidência a maneira como os dois críticos procuram pensar o continente latino-americano como contemporâneo à Europa e aos Estados Unidos, sem perder de vista as relações globais do capitalismo ou as especificidades da região. No caso dos debates culturais brasileiros, é também interessante como, ao retornarmos aos debates sobre dependência, encontramos respostas para críticas que foram feitas ao modelo materialista de análise cultural nos últimos anos. Silviano Santiago, em seu ensaio "Dependente mas universal”, para ficar num exemplo canônico, afirma que a crítica materialista apresenta "duas decalagens capitais: uma temporal (o atraso de uma cultura com relação à outra) e uma qualitativa (a falta de originalidade nos produtos da cultura dominada)" (1980, p. 21). Como deixou claro nossa leitura, entretanto, são exatamente essas decalagens que a teoria da dependência e o próprio Schwarz relativizam, dando a elas novos significados. Isto é, a cultura periférica para o crítico é contemporânea à central e, portanto, não é atrasada, mas sim parte integrante do mesmo sistema: isto é, a periferia é central para o funcionamento do centro e a manutenção de sua hegemonia. O centro, entretanto, continua sendo centro, no sentido de que é ali que se concentram a maior parte das forças que dirigem o capital global e as trocas culturais contemporâneas. Atrasado, de qualquer maneira, não é um termo aplicado por estes críticos da maneira criticada por Santiago, pois atraso e avanço são, para a dependência, questões sociais e não temporais. O mesmo vale para a contraposição de que haveria na crítica materialista uma dificuldade em reconhecer avanços e positividades nas produções culturais periféricas. Como mostramos, 
a teoria da dependência procura exatamente devolver dinamicidade aos processos políticos, econômicos e culturais da América Latina; e Aníbal Quijano tem focado seus estudos na necessidade de se recuperar, dentro de uma matriz materialista, culturas subalternas. Ainda assim, tributários de formações ideológicas produzidas alhures, nossas produções culturais têm algo de dependentes, o que não impede a cultura da América Latina pós-colonial de produzir desenvolvimentos e respostas próprias aos problemas, limitações e desafios que encontra em seu caminho. Para ela ser realmente independente, antes teríamos de reavaliar a "colonialidade do poder" que perpassa nosso pensamento. Até que isso aconteça, o termo dependente serve para nos lembrar que, ainda que resultados estéticos possam ser criativos e positivos, as condições de subdesenvolvimento que os possibilitaram são sempre negativas. Isto é, o "entre lugar" não é exatamente um lugar socialmente privilegiado, se quisermos recuperar o termo do próprio Santiago. A diferença pela diferença, como aponta Schwarz, tem um ar moderno, mas não funciona necessariamente como uma categoria crítica (1987, p. 36). Sublimação e fruição estética, ademais, não resolvem o problema da fome, pobreza ou analfabetismo, que são problemas que Schwarz e Quijano também tentam levar em conta em seus modelos.

Ainda assim, a crítica de Santiago toca em um ponto importante. A perspectiva materialista no Brasil parece ter prestado pouca atenção em questões de identidade e diversidade, as quais poderiam combater seu ponto de origem e sua perspectiva eurocêntrica (ou sua "colonialidade," para recuperarmos o termo de Quijano). Nas palavras de Santiago, a crítica marxista tem proposto "a racionalidade analítica ou dialética como forma inevitável da integração ao todo do indígena e do negro; a complementaridade como processo de uniformização e totalização da diferença" (1980, p. 22). Isto é, no processo de totalização teórico, a crítica cultural teria participado do apagamento das próprias culturas que, em tese, devido à sua preocupação com subjugados e subalternos, deveria ter ajudado a elevar e a recuperar. É possível, contudo, pensar questões de identidade e diversidade sem perdermos o pé nos problemas reais do subdesenvolvimento. Nesse sentido, a comparação dos modelos de Schwarz e de Quijano parece de grande valia, pois recoloca essas questões no debate cultural latino-americano a partir de uma matriz histórico-materialista, pensada de acordo com as necessidades do próprio continente. Ainda assim, para Quijano, a única maneira de combatermos o caráter colonial de nosso próprio pensamento seria combatendo nossa 
dependência epistemológica, a qual nos remete a preconceitos históricos intrínsecos do pensamento ocidental com o qual nos identificamos. A tarefa, portanto, é bastante complicada. Para romper esse ciclo, teríamos de recuperar a diversidade e riqueza das culturas que o colonialismo e o eurocentrismo que o sucedeu tentaram apagar para, então, tentarmos corrigir nossa própria perspectiva, nossas prioridades e ênfases; isto é, para que articulemos uma nova história intelectual latino-americana. Algo que, como deixa claro a "teoria da dependência", ganharia muito com diálogos feitos na própria periferia do sistema capitalista.

A comparação entre os trabalhos de Schwarz e Quijano parece apontar para um diálogo promissor, além de atestar para a importância de olharmos para a própria América Latina em busca de soluções para as questões que nos dizem respeito. Isto é, a resposta nem sempre está no centro. E, se as necessidades específicas de cada país determinam certas ênfases nos modelos teóricos nacionais, atentar para diferentes modelos pode nos ajudar a complicar aqueles que escolhemos utilizar, devolvendo uma dinamicidade a nossos debates e levando-nos a apurar nosso próprio olhar e senso crítico. Desse modo, se o modelo de Schwarz atenta para a escravidão a partir da problemática do trabalho e do favor, é certo que no Brasil, como no Peru, preconceito e identidade também são partes importantes desse fenômeno. A maneira pela qual elites oprimiram e dificultaram a formação de identidades outras que não as suas, também precisa ser estudada e é parte importante do processo de dependência epistemológica que o próprio Schwarz estuda. Precisamos, assim, atentar para o conhecimento ameríndio e africano que também nos formaram e as contribuições que eles podem trazer para nossos modelos teóricos, pois esta seria a única maneira de combatermos a "colonialidade do poder" de que somos reféns e culpados. As contribuições de Eduardo Viveiros de Castro eseus estudos sobre perspectivismoameríndio, por exemplo, seriam uma prova das possibilidades que tais estudos podem trazer. Um debate, não por acaso, que questiona a maneira pela qual integramos questões de identidade em nossas matrizes teóricas: "Se o multiculturalismo ocidental", escreve Viveiros de Castro, "é relativismo como política pública, o perspectivismo ameríndio seria, então, multiculturalismo como política cósmica" (1998, p. 472). Isto é, poderíamos, para começar, aprender com o perspectivismo, reavaliando o valor que damos, nos debates materialistas, para questões de identidade; algo aparentemente mais fácil no Peru, onde a forte presença de culturas pré-colombianas faz desta uma questão incontornável. 
O que importa perceber, no contexto deste ensaio, é como Quijano mostra que não precisamos abrir mão da crítica ao subdesenvolvimento para falarmos de identidade. E, mesmo que a história do Brasil seja diferente da do Peru, podemos aprender com seu modelo e repensá-lo para ler nossos próprios problemas, em que favor e escravidão tiveram um papel central, como mostra Schwarz. Ainda que no Brasil contemporâneo a questão indígena pareça mais diluída do que no Peru, isso não significa que não temos de levá-la em consideração, ampliando o modo como entendemos e pensamos a identidade. Recuperar o debate da dependência é, portanto, recuperar este tipo de trabalho colaborativo que pensa a América Latina de forma dinâmica, sem deixar de ser crítico; é uma maneira de pensar modelos teóricos de forma aberta sem deixar de lado um posicionamento crítico e de esquerda. E, vistos a partir da "teoria da dependência”, o caráter comparativo dos trabalhos de Schwarz e Quijano nos convida a pensar a América Latina tanto como diferença quanto como igualdade; abrindo um caminho para respondermos ao desafio de Jorge Schwartz a partir de debates que começamos há mais de trinta anos, mas que ainda estão longe de estarem resolvidos e que, muito provavelmente, só chegaremos perto de resolver se recuperarmos o impulso de pensar nossa história intelectual de forma comparada, dinâmica e crítica.

\section{REFERÊNCIAS BIBLIOGRÁFICAS}

AMANTE, Adriana. Poéticas y políticas del destierro: argentinos en Brasil en la época de Rosas. Buenos Aires: Fondo de Cultura Económica, 2010.

CARDOSO, Fernando Henrique. As ideias e seu lugar: ensaios sobre as teorias do desenvolvimento. Petrópolis: Vozes, 1993.

CARDOSO, Fernando Henrique; FALETTO, Enzo. Dependência e desenvolvimento na América Latina. Rio de Janeiro: Zahar, 1973.

CASTRO, Eduardo Viveiros de. Cosmological Deixis and Amerindian Perspectivism. The Journal of the Royal Anthropological Institute, Londres, n. 4.3, p. 469-488, set. 1998.

JAMESON, Fredric. The Modernist Papers. Nova York: Verso, 2007.

MARIÁTEGUI, José Carlos. Siete ensayos de interpretación de la realidad peruana. Barcelona: Editorial LinKgua, 2011.

MIGNOLO, Walter. The Geopolitics of Knowledge and The Colonial Difference. In: Coloniality at Large: Latin America and the Postcolonial Debate (org.: Mabel 
50 - Remate de Males 36.1

Moraña; Enrique Dussel; Carlos A. Jáuregui). Durham: Duke University Press, 2008, p. 225-258.

MORETTI, Franco. Conjectures on World Literature. In: Debating World Literature (org.: Christopher Prendergast). Nova York: Verso, 2004, p. 148-163.

QUIJANO, Aníbal. Colonialidad del poder, eurocentrismo y América Latina. In: La colonialidad del saber: eurocentrismo y ciencias sociales (org.: Edgardo Lander). Buenos Aires: CLACSO, 200o, p. 201-246.

QUIJANO, Aníbal; WALLERSTEIN, Imannuel. La americanidad como concepto, o América en el moderno sistema mundial. Revista Internacional de Ciencias Sociales, Paris, n. 134, p. 583-591, dez. 1992.

SALDAÑA-PORTILLO, María. The Revolutionary Imagination in the Americas and the Age of Development. Durham: Duke UP, 2003.

SANTIAGO, Silviano. Apesar de dependente, universal. In: Vale quanto pesa. Rio de Janeiro: Paz \& Terra, 1980, p. 13-24.

SCHWARTZ, Jorge. Abaixo Tordesilhas! Estudos Avançados, São Paulo, n. 7.17, p. 185-200, abr. 1993.

SCHWARZ, Roberto. As ideias fora do lugar. In: . Ao vencedor as batatas. São Paulo: Duas Cidades, 1981, p. 13-28.

SCHWARZ, Roberto. Nacional por subtração. In: Que horas são? São Paulo: Companhia das Letras, 1987, p. 29-48.

SCHWARZ, Roberto. Um seminário de Marx. In: . Sequências brasileiras. São Paulo: Companhia das Letras, 1999, p. 86-105. 